\title{
An Improved Steam Injection Model with the Consideration of Steam Override
}

\author{
Congge $\mathrm{He}^{1 *}$, Longxin $\mathrm{Mu}^{1}$, Zifei Fan ${ }^{1}$, Anzhu $\mathrm{Xu}^{1}$, Baoquan Zeng ${ }^{1}$, Zhongyuan $\mathrm{Ji}^{2}$ \\ and Haishui Han ${ }^{1}$ \\ ${ }^{1}$ Research Institute of Petroleum Exploration \& Development, PetroChina, 20 Xueyuan Road, Haidian, Beijing 100083 - PR China \\ ${ }^{2}$ China National Oil and Gas Exploration \& Development Corporation, 6 Fuchengmen Road, Xicheng, Beijing 100034 - PR China \\ e-mail: hecongge1988@163.com \\ * Corresponding author
}

\begin{abstract}
The great difference in density between steam and liquid during wet steam injection always results in steam override, that is, steam gathers on the top of the pay zone. In this article, the equation for steam override coefficient was firstly established based on van Lookeren's steam override theory and then radius of steam zone and hot fluid zone were derived according to a more realistic temperature distribution and an energy balance in the pay zone. On this basis, the equation for the reservoir heat efficiency with the consideration of steam override was developed. Next, predicted results of the new model were compared with these of another analytical model and CMG STARS (a mature commercial reservoir numerical simulator) to verify the accuracy of the new mathematical model. Finally, based on the validated model, we analyzed the effects of injection rate, steam quality and reservoir thickness on the reservoir heat efficiency. The results show that the new model can be simplified to the classic model (Marx-Langenheim model) under the condition of the steam override being not taken into account, which means the Marx-Langenheim model is corresponding to a special case of this new model. The new model is much closer to the actual situation compared to the Marx-Langenheim model because of considering steam override. Moreover, with the help of the new model, it is found that the reservoir heat efficiency is not much affected by injection rate and steam quality but significantly influenced by reservoir thickness, and to ensure that the reservoir can be heated effectively, the reservoir thickness should not be too small.
\end{abstract}

Résumé - Un modèle amélioré d'injection de vapeur prenant en compte la surcharge de vapeur — La différence de densité entre la vapeur et le liquide lors de l'injection de vapeur humide conduit toujours à un débordement de vapeur, en d'autres termes, la vapeur s'accumule sur le dessus de la zone de production. Dans cet article, l'équation pour le coefficient de surcharge de vapeur a d'abord été établie sur la base de la théorie de la surcharge de vapeur de van Lookeren, puis le rayon de la zone de vapeur et la zone de fluide chaud ont été dérivés selon une distribution de température plus réaliste et un bilan énergétique dans la zone de production. Sur cette base, l'équation d'efficacité thermique du réservoir en tenant compte de la surpression de la vapeur d'eau a été développée. Par la suite, les résultats prévus par le nouveau modèle ont été comparés à ceux d'un autre modèle analytique et à CMG STARS (un simulateur numérique à réservoir commercial reconnu) pour vérifier la précision du nouveau modèle mathématique. Enfin, sur la base du modèle validé, nous avons analysé les effets du taux d'injection, de la qualité de la vapeur et de la densité du réservoir sur l'efficacité thermique du réservoir. Les résultats montrent que le nouveau modèle peut être simplifié par rapport au modèle classique (modèle de Marx-Langenheim) à condition que la 
surcharge de vapeur ne soit pas prise en compte, ce qui signifie que le modèle de Marx-Langenheim correspond à une exception de ce nouveau modèle. Le nouveau modèle est beaucoup plus proche de la situation réelle que le modèle de Marx-Langenheim de par sa prise en compte de la surcharge de vapeur. De plus, à l'aide du nouveau modèle, on constate que le rendement calorifique du réservoir est peu affecté par le taux d'injection et la qualité de la vapeur, mais est influencé de façon significative par l'épaisseur du réservoir et pour assurer un chauffage efficace par le réservoir, l'épaisseur de celui-ci ne doit pas être trop petite.

\section{NOMENCLATURE}

a Temperature gradient of the hot fluid zone, ${ }^{\circ} \mathrm{C} / \mathrm{m}$

$A_{\mathrm{RD}}$

$A_{\mathrm{s} 1}$

$A_{\mathrm{s} 2}$

$A_{\mathrm{h} 1}$

$A_{\mathrm{h} 2}$

$A^{\prime}$

$C_{\mathrm{p}}$

$g$

$H$

$H_{\text {st }}$

$h_{\mathrm{w}}$

$h_{\mathrm{D}}$

$i_{\mathrm{s}}$

$k_{\mathrm{st}}$

$k_{\mathrm{o}}$

$L(\cdot)$

$L_{\mathrm{v}}$

$m$

$M^{*}$

$M_{\mathrm{R}}$

$q$

$Q_{\text {se }}$

$Q_{\mathrm{sb}}$

$Q_{\text {sv }}$

$Q_{\text {si }}$

$Q_{\text {he }}$

$Q_{\mathrm{hb}}$

$Q_{\mathrm{hv}}$

$Q_{\text {hi }}$

$Q_{\text {os }}$

$Q_{\text {oh }}$

$r$

$r_{\mathrm{es}}$

$r_{\mathrm{bs}}$

Dimensionless shape factor, dimensionless

Area of steam-zone top, $\mathrm{m}^{2}$

Area of steam-zone bottom, $\mathrm{m}^{2}$

Area of hot-fluid-zone top, $\mathrm{m}^{2}$

Area of hot-fluid-zone bottom, $\mathrm{m}^{2}$

Pseudo area of hot-fluid-zone bottom, $\mathrm{m}^{2} \cdot{ }^{\circ} \mathrm{C}$

Heat capacity, $\mathrm{J} /\left(\mathrm{kg} \cdot{ }^{\circ} \mathrm{C}\right)$

Gravitational acceleration, $\mathrm{m}^{2} / \mathrm{s}$

Thickness of reservoir, $m$

Thickness of steam zone, $\mathrm{m}$

Specific enthalpy of water, $\mathrm{J} / \mathrm{kg}$

Ratio of the latent heat of the steam to the sensible heat, dimensionless

Injection rate of wet steam, $\mathrm{kg} / \mathrm{s}$

Effective permeability of steam, $\mathrm{mD}$

Effective permeability of oil, $\mathrm{mD}$

Laplace transformation function

Latent heat of vaporization of steam, $\mathrm{J} / \mathrm{kg}$

Steam override coefficient, dimensionless

The mobility ratio at reservoir temperature, dimensionless

Heat capacity of reservoir, $\mathrm{J} /\left(\mathrm{m}^{3} \cdot{ }^{\circ} \mathrm{C}\right)$

Heat loss rate per unit area, $\mathrm{J} /\left(\mathrm{m}^{2} \cdot \mathrm{s}\right)$

Heat loss rate to overburden of steam zone, $\mathrm{J} / \mathrm{s}$

Heat loss rate to underburden of steam zone, $\mathrm{J} / \mathrm{s}$

Heat growth rate of steam zone, $\mathrm{J} / \mathrm{s}$

Heat injection rate of steam zone, $\mathrm{J} / \mathrm{s}$

Heat loss rate to overburden of hot fluid zone, $\mathrm{J} / \mathrm{s}$

Heat loss rate to underburden of hot fluid zone, $\mathrm{J} / \mathrm{s}$

Heat growth rate of hot fluid zone, $\mathrm{J} / \mathrm{s}$

Heat injection rate of hot fluid zone, $\mathrm{J} / \mathrm{s}$

Heat growth of steam zone, $J$

Heat growth of hot fluid zone, $\mathrm{J}$

Radial distance into reservoir, $m$

Radius of steam-zone top, $m$

Radius of steam-zone bottom, $\mathrm{m}$ $r_{\mathrm{eh}} \quad$ Radius of hot-fluid-zone top, $\mathrm{m}$

$r_{\text {bh }} \quad$ Radius of hot-fluid-zone bottom, $\mathrm{m}$

$S \quad$ Variable in Laplace space

$s_{\text {oi }} \quad$ Initial oil saturation, dimensionless

$t \quad$ Injection time, $\mathrm{d}$

$T_{\mathrm{s}} \quad$ Steam temperature, ${ }^{\circ} \mathrm{C}$

$T_{\mathrm{i}} \quad$ Initial reservoir temperature, ${ }^{\circ} \mathrm{C}$

$t_{\mathrm{D}} \quad$ Dimensionless time, dimensionless

$T_{\mathrm{e}}(r) \quad$ Temperature of hot-fluid-zone top at $r,{ }^{\circ} \mathrm{C}$

$T_{\mathrm{b}}(r) \quad$ Temperature of hot-fluid-zone bottom at $r,{ }^{\circ} \mathrm{C}$

$V_{\mathrm{s}} \quad$ Volume of the steam zone, $\mathrm{m}^{3}$

$V_{\mathrm{h}} \quad$ Volume of the hot fluid zone, $\mathrm{m}^{3}$

$x \quad$ Steam quality at the bottomhole, dimensionless

$w_{\mathrm{o}}\left(r_{\mathrm{es}}\right) \quad$ Oil mass flow rate at $r_{\mathrm{es}}, \mathrm{kg} / \mathrm{s}$

$w_{\mathrm{st}}\left(r_{\mathrm{bs}}\right) \quad$ Steam mass flow rate at $r_{\mathrm{bs}}, \mathrm{kg} / \mathrm{s}$

$w_{\text {sti }} \quad$ Steam mass flow rate at injection end, $\mathrm{kg} / \mathrm{s}$

\section{GREEK LETTERS}

$\alpha_{\mathrm{s}} \quad$ Thermal diffusivity of the overburden and underburden, $\mathrm{m}^{2} / \mathrm{d}$

$\beta \quad$ Factor, dimensionless

$\delta \quad$ Instant at which the boundary becomes exposed to the hot fluid, $d$

$\eta \quad$ Reservoir heat efficiency, dimensionless

$\lambda_{\mathrm{s}} \quad$ Thermal conduction coefficient of overburden and underburden, $\mathrm{W} /\left(\mathrm{m} \cdot{ }^{\circ} \mathrm{C}\right)$

$\mu_{\text {st }} \quad$ Steam viscosity, $\mathrm{mPa} \cdot \mathrm{s}$

$\mu_{\mathrm{o}}^{*} \quad$ Oil viscosity at steam temperature, $\mathrm{mPa} \cdot \mathrm{s}$

$\rho \quad$ Density, $\mathrm{kg} / \mathrm{m}^{3}$

$\varphi \quad$ Reservoir porosity

\section{SUBSCRIPTS}

st Steam

o Oil

w Water

r Sand rock 


\section{INTRODUCTION}

Under initial reservoir conditions, heavy oil that has viscosity between 50 to 10000 centipoises plays an important role in crude oil reserve [1-3]. Despite its immense potential, it is a great challenge to recover heavy oil due to its low mobility. Thermal recovery methods have been used during the past decades to exploit heavy oil reservoirs because the viscosity of heavy oil changes rapidly with temperature. Engineers have applied methods such as cyclic steam stimulation $[4,5]$, steamflooding $[6,7]$ and steam assisted gravity drainage [8] to recover heavy oil. Since water has high latent heat of vaporization and specific heat capacity, wet steam, which is the steam/water mixture generated in the steam generators, is usually chosen as heat carrier. When the wet steam is transported from steam generators to the bottomhole of injection wells, much heat is lost. In other words, not all heat carried by wet steam from steam generators can enter and be used to heat the pay zone. Heat losses occur in at least three aspects in the wet steam injection process (shown in Fig. 1). Firstly, as wet steam flows through the surface pipeline system, that distributes wet steam from steam generators to the wellhead of injection wells, a part of heat is lost from the fluid to the surrounding atmosphere through surface pipeline wall and insulation materials [9]. Since generators are usually set up close to injection wells, the fraction of carried heat lost in the surface pipeline system is infinitesimally small and can be neglected. Secondly, during wet steam flows from the wellhead to the bottomhole of injection wells, a part of heat is lost from the wet steam to surrounding formation [10]. Thirdly, when the wet steam reaches the bottomhole of injection wells and enters the pay zone, heat loss also occurs, that is, a part of heat losses to the overburden and underburden [11].

With constant development, studies of the wellbore heat efficiency in the hot fluid injection process have been already relatively perfect. Accurately estimating the distribution of thermophysical properties of wet steam (i.e. steam pressure, quality and pressure) in wellbores is of great significance to the prediction of wellbore heat efficiency. Ramey [12] was the first to present an expression for fluid temperature as a function of well depth and injection time by assuming that heat transfer in the wellbore is steady-state, while heat transfer to the formation is unsteady radial conduction. Satter [13] improved Ramey's analytical model by making the over-all heat transfer coefficient dependent on depth and taking into account the effect of condensation, which is of practical significance in wet steam injection process. Using this concept, he presented a method for estimating steam quality distribution. Holst and Flock [14] further improved the Ramey's and Satter's model by including friction losses and kinetic energy effects. Gu et al. [15-17] presented a solution for calculating steam pressure not by dividing flow patterns and determining transition criteria but by the law of energy conservation, and based on it a comprehensive mathematical model was derived for estimating the wellbore heat efficiency.

After some heat lost in the wellbore, the wet steam enters the pay zone where steam releases its latent heat and then condenses into water while cold heavy oil is heated. This results in three regions being created in the pay zone: steam zone, hot fluid zone and unheated zone (Fig. 1) [18]. The reservoir heat efficiency, namely, the fraction of injected heat retained in the pay zone, usually obtained by the heat balance equations in terms of the temperature distribution in the pay zone. Baker [19] indicates the true temperature distribution of pay zone (illustrated by the dotted line in Fig. 2) in the wet steam injection process by experimental study. That is, the temperature in the steam zone is constant and equals to the injected steam temperature and the temperature in the hot fluid zone gradually decreases from the injected steam temperature to the initial reservoir temperature. Marx and Langenheim [20] established an analytical mathematical model for heated area and reservoir heat efficiency based on the simple vertical front displacement and heat balance between injected heat, heat loss to overburden and underburden and heat retained in the pay zone. Their work is very classic in determining the reservoir heat efficiency and has been used extensively since. However, their study assumed that the temperature within the heated region equals to the injected steam temperature (shown by black solid line in Fig. 2), which does not take into account the temperature decrease in the hot fluid zone, and ignored the steam override effect, which is a very common phenomenon in wet steam injection process. As the steam enters the pay zone it tends to rise to the top because of the significant difference in density between steam and liquid. van Lookeren [21] derived the equation for steam zone front by a description of changes in potential in the steam and hot fluid zones, and this method is adopted to calculate the steam override in this paper. Doscher and Ghassemi [22], Neuman [23] and Vogel [24] proposed models considering steam override effect. However, these models assumed that all the injected steam goes immediately to the top of the pay zone, which is not completely in accord with the actual situation, and these models represented the heat efficiency of steam zone only because of ignoring the heat contained in the hot fluid zone.

The purpose of this article is to present an analytical model for accurately predicting the reservoir heat efficiency with the consideration of steam override in wet steam injection process. In this paper, the equation for steam override coefficient is firstly established based on van Lookeren's steam override theory and then radius of steam zone and hot fluid zone are derived according to a more realistic temperature distribution and an energy balance in the pay zone. 


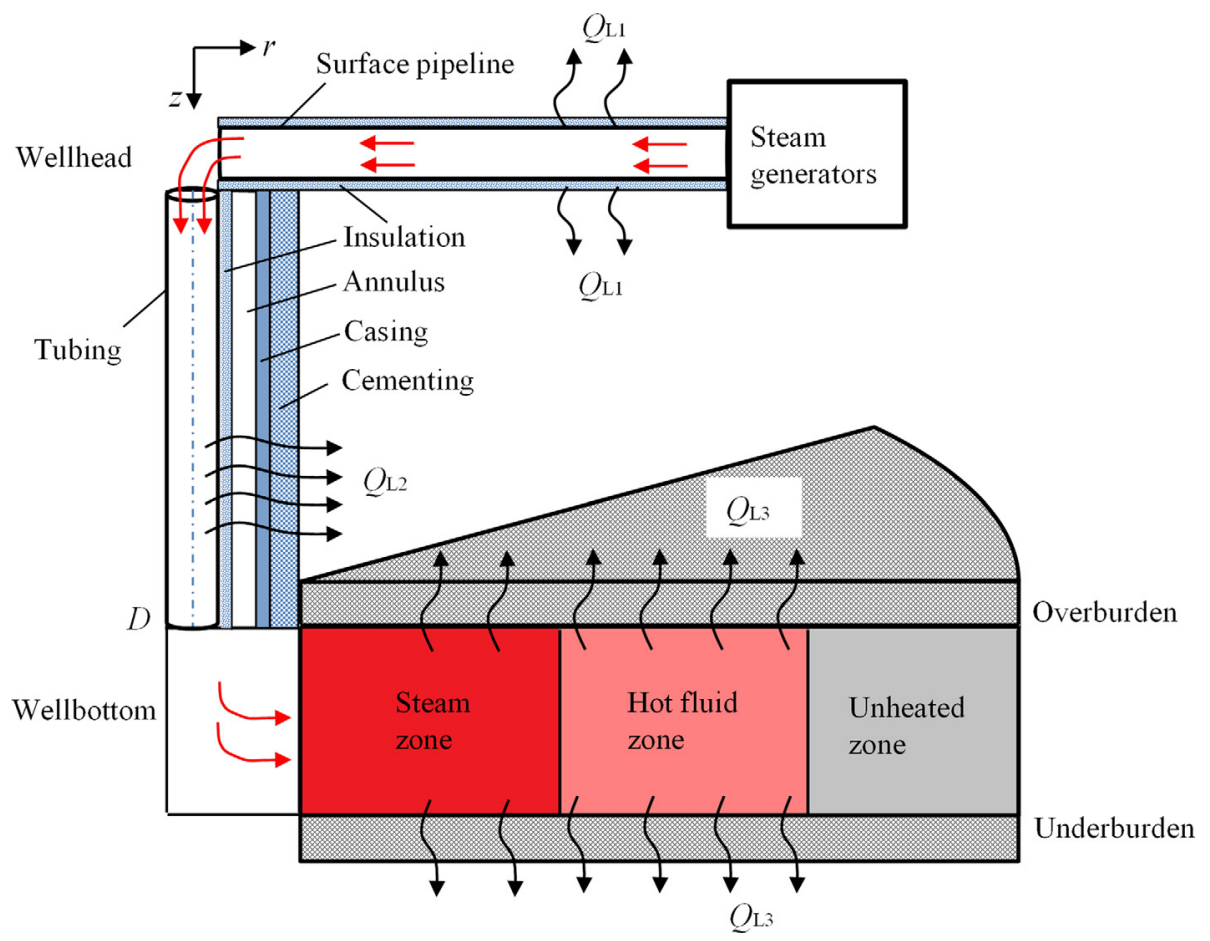

Figure 1

Schematic of heat losses in wet steam injection process (vertical front displacement model).

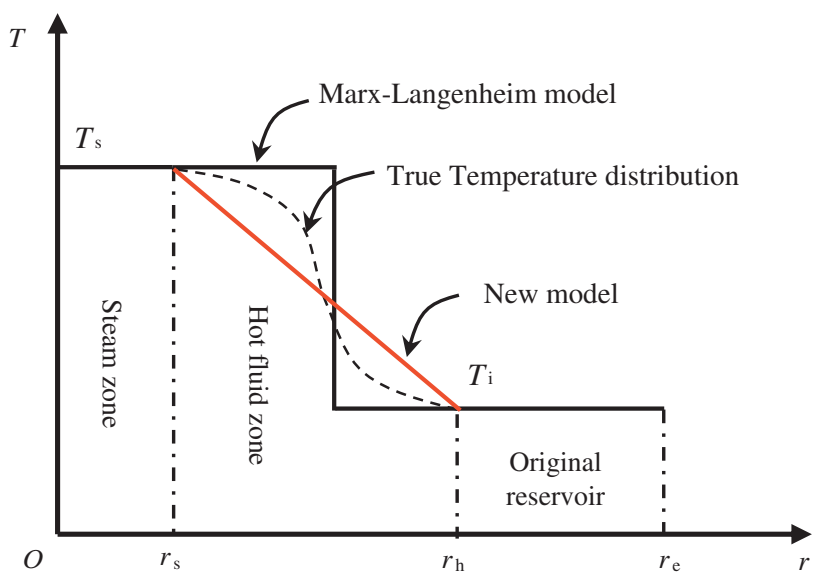

Figure 2

True temperature distribution of pay zone (dotted line) and the step approximation in Marx-Langenheim model (black solid line) and the linear approximation (red solid line) in this new model.

On this basis, the equation for the reservoir heat efficiency considering steam override is developed. Next, the accuracy of the mathematical model is verified by comparisons of simulated results with another analytical model and a thermal simulator. Finally, based on the validated model, detailed analyses of the influential factors of reservoir heat efficiency are made. There are three main features between our approach and previous researches: (1) the injected heat contained in the hot fluid zone ahead of the steam front is considered, in other words, the reservoir heat efficiency in this paper includes both the steam zone and hot fluid zone instead of steam zone only; (2) the temperature of hot fluid zone is considered to linearly decrease from injected steam temperature to the initial reservoir temperature, rather than to be constant with the value of injected steam temperature; (3) to take into account the steam override effect, the steam zone is considered as the frustum of a cone instead of a cylinder, which is more coincident with the actual conditions.

\section{MATHEMATICAL MODEL}

In this paper, the following assumptions have been made to determine the reservoir heat efficiency resulting from injection of wet steam into a pay zone and heat losses from it into the adjacent strata. 

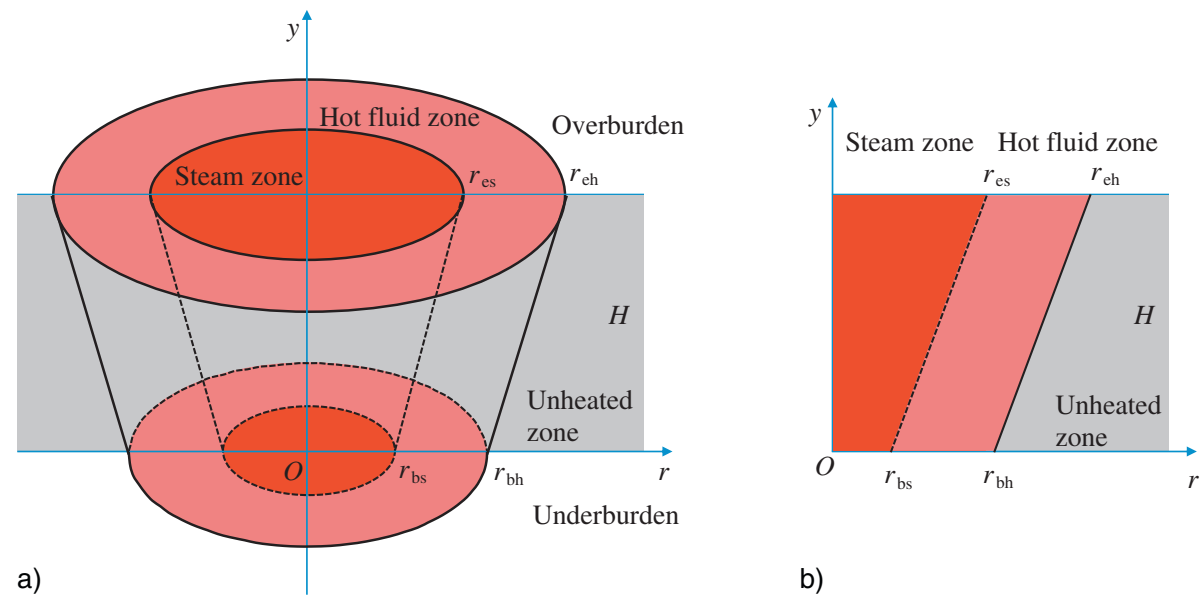

Figure 3

Schematic of steam zone and hot fluid zone a) and fronts of steam zone and hot fluid zone b) considering steam override in wet steam injection process.

(1) The pay zone is assumed to be horizontal, homogeneous, isotropic and uniform thickness, and assumed to have a constant and uniform heat capacity.

(2) The injection rate, steam temperature and steam quality at the bottom of the injection well do not change with injection time.

(3) The lost heat in the pay zone is assumed to flow into the overburden and underburden by conduction only and the thermal conductivity and the heat capacity are the same in both the overburden and underburden.

(4) The steam zone is assumed to have the shape of the frustum of a cone and the fronts of the steam zone and the hot fluid zone are parallel to each other (as shown in Fig. 3).

(5) The temperature is constant and equals to the injected steam temperature in the steam zone and linearly decreases from the injected steam temperature to the initial reservoir temperature in the hot fluid zone as shown by red solid line in Figure 2. Besides, the temperature gradient of the hot fluid zone in radius at different reservoir vertical positions is constant.

\subsection{Steam Override Coefficient}

The significant difference in density between steam and liquid during wet steam injection results in steam override that steam gathers on the top of the reservoir. According to the van Lookeren's steam override theory, the equation for steam zone front as a function of radius can be expressed as

$$
\frac{H_{\mathrm{st}}}{A_{\mathrm{RD}} H}=\left[\left(\ln \frac{r_{\mathrm{es}}}{r}-\frac{1}{2}+\frac{1}{2} \frac{r^{2}}{r_{\mathrm{es}}^{2}}\right)\left(1-M^{*}\right)\right]^{\frac{1}{2}}
$$

where $H$ and $H_{\text {st }}$ are the thickness of reservoir and steam zone, respectively; $r_{\mathrm{es}}$ and $r_{\mathrm{bs}}$ are the radii of steam-zone top and steam-zone bottom, respectively; $r$ is the radial distance into reservoir; $M^{*}$ and $A_{\mathrm{RD}}$ are the mobility ratio at reservoir temperature and the dimensionless shape factor, respectively, which can be calculated from

$$
M^{*}=\frac{\mu_{\mathrm{o}}^{*} k_{\mathrm{st}} \rho_{\mathrm{st}} w_{\mathrm{o}}\left(r_{\mathrm{es}}\right)}{\mu_{\mathrm{st}} k_{\mathrm{o}} \rho_{\mathrm{o}} w_{\mathrm{st}}\left(r_{\mathrm{bs}}\right)}
$$

$$
A_{\mathrm{RD}}=\sqrt{\frac{\mu_{\mathrm{st}} w_{\mathrm{sti}}}{\pi\left(\rho_{\mathrm{o}}-\rho_{\mathrm{st}}\right) \mathrm{g} H^{2} k_{\mathrm{st}} \rho_{\mathrm{st}}} \times 10^{12}}
$$

where $\mu_{\mathrm{st}}$ and $\mu_{\mathrm{o}}^{*}$ are the steam viscosity and oil viscosity at steam temperature, respectively; $\rho_{\text {st }}$ and $\rho_{\mathrm{o}}$ are the densities of steam and oil, respectively; $k_{\mathrm{st}}$ and $k_{\mathrm{o}}$ are the effective permeability of steam and oil, respectively; $w_{\mathrm{o}}\left(r_{\mathrm{es}}\right), w_{\mathrm{st}}\left(r_{\mathrm{bs}}\right)$ and $w_{\text {sti }}$ are the oil mass flow rate at $r_{\text {es }}$, the steam mass flow rate at $r_{\mathrm{bs}}$ and the steam mass flow rate at injection end; $g$ is the gravitational acceleration.

Through Equation (1), the steam zone front of different $A_{\mathrm{RD}}$ with $M^{*}=0$ is shown in Figure 4. It is obvious that the degree of steam override is more severe as $A_{\mathrm{RD}}$ decreases.

The steam override coefficient, $m$, is defined as the ratio of the radius of steam-zone top and that of steam-zone bottom, namely, $m=r_{\mathrm{es}} / r_{\mathrm{bs}}$. In addition, the thickness of steam zone equals to the thickness of reservoir $\left(H_{\text {st }}=H\right)$ at the end of the steam/liquid interface $\left(r=r_{\mathrm{bs}}\right)$. Substituting these equations into Equation (1) yields 


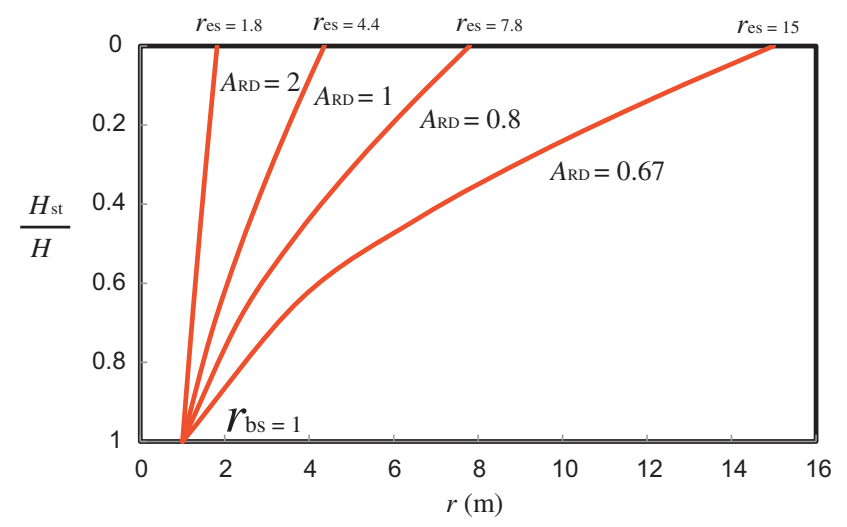

Figure 4

Steam zone front of different $A_{\mathrm{RD}}$ with $M^{*}=0\left(A_{\mathrm{RD}}=0.67,0.8\right.$, $1,2)$.

$$
\frac{1}{A_{\mathrm{RD}}^{2}\left(1-M^{*}\right)}=\ln m-\frac{1}{2}+\frac{1}{2 m^{2}}
$$

Therefore, the steam override coefficient, $m$, is the function of $M^{*}$ and $A_{\mathrm{RD}}$ and can be obtained by solving Equation (4).

\subsection{Radius of Steam Zone and Hot Fluid Zone}

\subsubsection{Radius of Steam Zone}

Carslaw and Jaeger [25] built the heat loss model with constant temperature boundary and the heat loss rate per unit area is

$$
q=\frac{\lambda_{\mathrm{s}}\left(T_{\mathrm{s}}-T_{\mathrm{i}}\right)}{\sqrt{\pi \alpha_{\mathrm{s}} t}}
$$

where $q$ is the heat loss rate per unit area; $\lambda_{\mathrm{s}}$ is the thermal conduction coefficient of overburden and underburden; $\alpha_{\mathrm{s}}$ is thermal diffusivity of the overburden and underburden; $t$ is the injection time; $T_{\mathrm{s}}$ is the injected steam temperature; $T_{\mathrm{i}}$ is the initial reservoir temperature.

The steam zone enlarges as the injection time increases and the heat loss rate changes over time. Hence, the heat loss rate of steam zone to the overburden and underburden respectively are calculated by

$$
\begin{gathered}
Q_{\mathrm{se}}=\int_{0}^{A_{\mathrm{s} 1}} \frac{\lambda_{\mathrm{s}}\left(T_{\mathrm{s}}-T_{\mathrm{i}}\right)}{\sqrt{\pi \alpha_{\mathrm{s}} t}} \mathrm{~d} A_{\mathrm{s} 1} \\
Q_{\mathrm{sb}}=\int_{0}^{A_{\mathrm{s} 2}} \frac{\lambda_{\mathrm{s}}\left(T_{\mathrm{s}}-T_{\mathrm{i}}\right)}{\sqrt{\pi \alpha_{\mathrm{s}}}} \mathrm{d} A_{\mathrm{s} 2}
\end{gathered}
$$

where $Q_{\text {se }}$ is the heat loss rate to the overburden of steam zone; $Q_{\mathrm{sb}}$ is the heat loss rate to the underburden of steam zone; $A_{\mathrm{s} 1}$ is the area of steam-zone top; $A_{\mathrm{s} 2}$ is the area of steam-zone bottom.

The areas of steam-zone top and steam-zone bottom satisfy the relationship of $A_{\mathrm{s} 1}=m^{2} A_{\mathrm{s} 2}$. Thus, by changing the integral variable into time in Equations (6) and (7), we can obtain the sum of the heat loss rate of the steam zone to the overburden and to the underburden as follows

$$
Q_{\mathrm{se}}+Q_{\mathrm{sb}}=\int_{0}^{t} \frac{\lambda_{\mathrm{s}}\left(T_{\mathrm{s}}-T_{\mathrm{i}}\right)}{\sqrt{\pi \alpha_{\mathrm{s}}(t-\delta)}}\left(m^{2}+1\right) \frac{\mathrm{d} A_{\mathrm{s} 2}}{\mathrm{~d} \delta} \mathrm{d} \delta
$$

where $\delta$ is the instant at which the cold boundary becomes exposed to the hot fluid.

Assuming that the shape of the steam zone is the frustum of a cone, whose volume is given by $V_{\mathrm{s}}=H\left(A_{\mathrm{s} 1}+\right.$ $\left.A_{\mathrm{s} 2}+\sqrt{A_{\mathrm{s} 1} A_{\mathrm{s} 2}}\right) / 3$, the heat growth rate of steam zone can be calculated by

$Q_{\mathrm{sv}}=M_{\mathrm{R}}\left(T_{\mathrm{s}}-T_{\mathrm{i}}\right) \frac{\mathrm{d} V_{\mathrm{s}}}{\mathrm{d} t}=\frac{H}{3} M_{\mathrm{R}}\left(T_{\mathrm{s}}-T_{\mathrm{i}}\right)\left(m^{2}+m+1\right) \frac{\mathrm{d} A_{\mathrm{s} 2}}{\mathrm{~d} t}$

where $Q_{\mathrm{sv}}$ is the heat growth rate of steam zone; $V_{\mathrm{s}}$ is the volume of steam zone; $M_{\mathrm{R}}$ is the heat capacity of reservoir, which can be expressed as

$$
M_{\mathrm{R}}=(1-\varphi) \rho_{\mathrm{r}} C_{\mathrm{pr}}+\varphi\left[\rho_{\mathrm{o}} s_{\mathrm{oi}} C_{\mathrm{po}}+\rho_{\mathrm{w}}\left(1-s_{\mathrm{oi}}\right) C_{\mathrm{pw}}\right]
$$

where $\varphi$ is the reservoir porosity; $\rho_{\mathrm{r}}$ and $\rho_{\mathrm{w}}$ are the densities of sand rock and water, respectively; $s_{\mathrm{oi}}$ is the initial oil saturation; $C_{\mathrm{pr}}, C_{\mathrm{po}}$ and $C_{\mathrm{pw}}$ are the heat capacities of sand rock, oil and water, respectively.

The heat injection rate of steam zone is

$$
Q_{\mathrm{si}}=i_{\mathrm{s}} x L_{\mathrm{V}}
$$

where $Q_{\mathrm{si}}$ is the heat injection rate of steam zone; $i_{\mathrm{s}}$ is the injection rate of wet steam; $x$ is the steam quality at the bottomhole; $L_{\mathrm{v}}$ is the latent heat of vaporization of steam at the bottomhole.

Based on the energy conservation principle [26], a heat balance of steam zone yields

$$
\begin{aligned}
i_{\mathrm{s}} x L_{\mathrm{V}}= & \int_{0}^{t} \frac{\lambda_{\mathrm{s}}\left(T_{\mathrm{s}}-T_{\mathrm{i}}\right)}{\sqrt{\pi \alpha_{\mathrm{s}}(t-\delta)}}\left(m^{2}+1\right) \frac{\mathrm{d} A_{\mathrm{s} 2}}{\mathrm{~d} \delta} \mathrm{d} \delta \\
& +\frac{H}{3} M_{\mathrm{R}}\left(T_{\mathrm{s}}-T_{\mathrm{i}}\right)\left(m^{2}+m+1\right) \frac{\mathrm{d} A_{\mathrm{s} 2}}{\mathrm{~d} t}
\end{aligned}
$$


Equation (12) belongs to Volterra integral equation of the second kind, and it can be solved by means of Laplace transformation. After Laplace transformation, Equation (12) becomes,

$$
\begin{aligned}
\frac{i_{\mathrm{s}} x L_{\mathrm{V}}}{S}= & \frac{\lambda_{\mathrm{s}}\left(T_{\mathrm{s}}-T_{\mathrm{i}}\right)}{\sqrt{\alpha_{\mathrm{s}}}}\left(m^{2}+1\right) \sqrt{S} L\left(A_{\mathrm{s} 2}\right) \\
& +\frac{H}{3} M_{\mathrm{R}}\left(T_{\mathrm{s}}-T_{\mathrm{i}}\right)\left(m^{2}+m+1\right) \operatorname{SL}\left(A_{\mathrm{s} 2}\right)
\end{aligned}
$$

where $S$ is a variable in Laplace space; $L(\cdot)$ is Laplace transformation function.

We get the solution in Laplace space,

$$
L\left(A_{\mathrm{s} 2}\right)=\frac{3 i_{\mathrm{s}} x L_{\mathrm{V}}}{M_{\mathrm{R}} H\left(T_{\mathrm{s}}-T_{\mathrm{i}}\right)\left(m^{2}+m+1\right)}\left(\frac{1}{S^{2}+b S^{\frac{3}{2}}}\right)
$$

where $b=\frac{3 \lambda_{s}\left(m^{2}+1\right)}{M_{\mathrm{R}} H\left(m^{2}+m+1\right) \sqrt{\alpha_{s}}}$.

Using inverse Laplace transformation, the area of steamzone bottom is

$$
\begin{aligned}
A_{\mathrm{s} 2}= & \frac{i_{\mathrm{s}} x L_{\mathrm{V}} M_{\mathrm{R}} H \alpha_{\mathrm{s}}\left(m^{2}+m+1\right)}{3\left(m^{2}+1\right)^{2} \lambda_{\mathrm{s}}^{2}\left(T_{\mathrm{s}}-T_{\mathrm{i}}\right)} \\
& \times\left[\mathrm{e}^{\beta t_{\mathrm{D}}} \operatorname{erfc}\left(\sqrt{\beta t_{\mathrm{D}}}\right)+2 \sqrt{\frac{\beta t_{\mathrm{D}}}{\pi}}-1\right]
\end{aligned}
$$

where $t_{\mathrm{D}}$ is dimensionless time, $t_{\mathrm{D}}=\frac{4 \lambda_{\mathrm{s}}{ }^{2}}{M_{\mathrm{R}}^{2} H^{2} \alpha_{\mathrm{s}}} t$; $\beta=\frac{9\left(m^{2}+1\right)^{2}}{4\left(m^{2}+m+1\right)^{2}}$.

With $A_{\mathrm{s} 2}=\pi r_{\mathrm{bs}}^{2}$, the radius of steam-zone bottom, $r_{\mathrm{bs}}$, is

$$
\begin{aligned}
r_{\mathrm{bs}}= & \sqrt{\frac{i_{\mathrm{s}} x L_{\mathrm{V}} M_{\mathrm{R}} H \alpha_{\mathrm{s}}\left(m^{2}+m+1\right)}{3 \pi\left(m^{2}+1\right)^{2} \lambda_{\mathrm{s}}^{2}\left(T_{\mathrm{s}}-T_{\mathrm{i}}\right)}} \\
& \times \sqrt{\mathrm{e}^{\beta t_{\mathrm{D}}} \operatorname{erfc}\left(\sqrt{\beta t_{\mathrm{D}}}\right)+2 \sqrt{\frac{\beta t_{\mathrm{D}}}{\pi}}-1}
\end{aligned}
$$

\subsubsection{Radius of Hot Fluid Zone}

Since we assumed that the temperature gradient of hot fluid zone in radius at different reservoir vertical positions is constant, the temperature distribution of hot-fluid-zone top and hot-fluid-zone bottom respectively are

$$
\begin{aligned}
& T_{\mathrm{e}}(r)=a\left(r-r_{\mathrm{es}}\right)+T_{\mathrm{s}} \\
& T_{\mathrm{b}}(r)=a\left(r-r_{\mathrm{bs}}\right)+T_{\mathrm{s}}
\end{aligned}
$$

where $T_{\mathrm{e}}(r)$ is the temperature of hot-fluid-zone top at $r$; $T_{\mathrm{b}}(r)$ is the temperature of hot-fluid-zone bottom at $r ; a$ is the temperature gradient of the hot fluid zone in radius, $a=\left(T_{\mathrm{i}}-T_{\mathrm{s}}\right) /\left(r_{\mathrm{bh}}-r_{\mathrm{bs}}\right) ; r_{\mathrm{bh}}$ is the radius of hot-fluid-zone bottom.

The heat loss rate of hot fluid zone to the overburden and to the underburden respectively are

$$
\begin{aligned}
Q_{\mathrm{he}} & =\int_{0}^{A_{\mathrm{h} 1}} \frac{\lambda_{\mathrm{s}}\left[T_{\mathrm{e}}(r)-T_{\mathrm{i}}\right]}{\sqrt{\pi \alpha_{\mathrm{s}} t}} \mathrm{~d} A_{\mathrm{s} 1} \\
& =\int_{r_{\mathrm{es}}}^{r_{\mathrm{eh}}} \frac{2 \sqrt{\pi} \lambda_{\mathrm{s}} r\left[a\left(r-r_{\mathrm{es}}\right)+T_{\mathrm{s}}-T_{\mathrm{i}}\right]}{\sqrt{\alpha_{\mathrm{s}} t}} \mathrm{~d} r
\end{aligned}
$$

$$
\begin{aligned}
Q_{\mathrm{hb}} & =\int_{0}^{A_{\mathrm{h} 2}} \frac{\lambda_{\mathrm{s}}\left[T_{\mathrm{b}}(r)-T_{\mathrm{i}}\right]}{\sqrt{\pi \alpha_{\mathrm{s}} t}} \mathrm{~d} A_{\mathrm{h} 2} \\
& =\int_{r_{\mathrm{bs}}}^{r_{\mathrm{bh}}} \frac{2 \sqrt{\pi} \lambda_{\mathrm{s}} r\left[a\left(r-r_{\mathrm{bs}}\right)+T_{\mathrm{s}}-T_{\mathrm{i}}\right]}{\sqrt{\alpha_{\mathrm{s}} t}} \mathrm{~d} r
\end{aligned}
$$

where $Q_{\text {he }}$ is the heat loss rate to the overburden of hot fluid zone; $Q_{\mathrm{hb}}$ is the heat loss rate to the underburden of hot fluid zone; $A_{\mathrm{h} 1}$ is the area of hot-fluid-zone top; $A_{\mathrm{h} 2}$ is the area of hot-fluid-zone bottom; $r_{\mathrm{eh}}$ is the radius of hot-fluid-zone top.

Let $r=\xi+m r_{\mathrm{bs}}-r_{\mathrm{bs}}$, and using integration by substitution, Equation (19) can be written as

$$
\begin{aligned}
Q_{\mathrm{he}}= & \int_{r_{\mathrm{es}}-(m-1) r_{\mathrm{bs}}}^{r_{\mathrm{eh}}-(m-1) r_{\mathrm{bs}}} \\
& \times \frac{2 \sqrt{\pi} \lambda_{\mathrm{s}}\left(\xi+m r_{\mathrm{bs}}-r_{\mathrm{bs}}\right)\left[a\left(\xi+m r_{\mathrm{bs}}-r_{\mathrm{bs}}-r_{\mathrm{es}}\right)+T_{\mathrm{s}}-T_{\mathrm{i}}\right]}{\sqrt{\alpha_{\mathrm{s}} t}} \mathrm{~d} \xi
\end{aligned}
$$

On account of $r_{\mathrm{es}}=m r_{\mathrm{bs}}-r_{\mathrm{bs}}$, and by changing the integral variable into time in Equations (20) and (21), we can get the sum of the heat loss rate of the hot fluid zone to the overburden and to the underburden as follows

$$
\begin{aligned}
& Q_{\mathrm{hb}}+Q_{\mathrm{he}} \\
& =\int_{0}^{t} \frac{2 \sqrt{\pi} \lambda_{\mathrm{s}}\left(2 r+m r_{\mathrm{bs}}-r_{\mathrm{bs}}\right)\left[a\left(r-r_{\mathrm{bs}}\right)+T_{\mathrm{s}}-T_{\mathrm{i}}\right]}{\sqrt{\alpha_{\mathrm{s}}(t-\delta)}} \frac{\mathrm{d} r}{\mathrm{~d} \delta} \mathrm{d} \delta
\end{aligned}
$$

The heat growth rate of hot fluid zone is

$$
\begin{aligned}
Q_{\mathrm{hv}} & =M_{\mathrm{R}}\left[a\left(r-r_{\mathrm{bs}}\right)+T_{\mathrm{s}}-T_{\mathrm{i}}\right] \frac{\mathrm{d} V_{\mathrm{h}}}{\mathrm{d} t} \\
& =M_{\mathrm{R}} H \pi\left[a\left(r-r_{\mathrm{bs}}\right)+T_{\mathrm{s}}-T_{\mathrm{i}}\right]\left(2 r+m r_{\mathrm{bs}}-r_{\mathrm{bs}}\right) \frac{\mathrm{d} r}{\mathrm{~d} t}
\end{aligned}
$$

where $Q_{\mathrm{hv}}$ is the heat growth rate of hot fluid zone; $V_{\mathrm{h}}$ is the volume of the hot fluid zone. 
The heat injection rate of hot fluid zone is

$$
Q_{\mathrm{hi}}=i_{\mathrm{s}} h_{\mathrm{w}}
$$

where $Q_{\mathrm{hi}}$ is the heat injection rate of hot fluid zone; $h_{\mathrm{w}}=\left(h_{\mathrm{w}}\right)_{T}-\left(h_{\mathrm{w}}\right)_{T=T \mathrm{r}},\left(h_{\mathrm{w}}\right)_{T}$ is the specific enthalpy of water at the bottomhole fluid temperature, and $\left(h_{\mathrm{w}}\right)_{T=T \mathrm{r}}$ is the specific enthalpy of water at the reservoir temperature.

Let $\quad \mathrm{d} A^{\prime}=\pi\left(2 r+m r_{\mathrm{bs}}-r_{\mathrm{bs}}\right)\left[a\left(r-r_{\mathrm{bs}}\right)+T_{\mathrm{s}}-T_{\mathrm{i}}\right] \mathrm{d} r$, based on the energy conservation principle, a heat balance of hot fluid zone yields

$$
i_{\mathrm{s}} h_{\mathrm{w}}=\int_{0}^{t} \frac{2 \lambda_{\mathrm{s}}}{\sqrt{\pi \alpha_{\mathrm{s}}(t-\delta)}} \frac{\mathrm{d} A^{\prime}}{\mathrm{d} \delta} \mathrm{d} \delta+M_{\mathrm{R}} H \frac{\mathrm{d} A^{\prime}}{\mathrm{d} t}
$$

where $A^{\prime}$ is the pseudo area of hot-fluid-zone bottom.

With Laplace transformation and inverse Laplace transformation for Equation (25), we can get

$$
A^{\prime}=\frac{i_{\mathrm{s}} h_{\mathrm{w}} M_{\mathrm{R}} H \alpha_{\mathrm{s}}}{4 \lambda_{\mathrm{s}}^{2}}\left[\mathrm{e}^{t_{\mathrm{D}}} \operatorname{erfc}\left(\sqrt{t_{\mathrm{D}}}\right)+2 \sqrt{\frac{t_{\mathrm{D}}}{\pi}}-1\right]
$$

Meanwhile, the pseudo area of hot-fluid-zone bottom, $A^{\prime}$, can be written as

$$
\begin{aligned}
A^{\prime} & =\int_{r_{\mathrm{bs}}}^{r_{\mathrm{bh}}} \mathrm{d} A^{\prime} \\
& =\int_{r_{\mathrm{bs}}}^{r_{\mathrm{bh}}} \pi\left(2 r+m r_{\mathrm{bs}}-r_{\mathrm{bs}}\right)\left[a\left(r-r_{\mathrm{bs}}\right)+T_{\mathrm{s}}-T_{\mathrm{i}}\right] \mathrm{dr} \\
& =\pi\left(a_{1} r_{\mathrm{bh}}{ }^{2}+b_{1} r_{\mathrm{bh}}+c_{1}\right)
\end{aligned}
$$

where $a_{1}=\frac{1}{3}\left(T_{\mathrm{s}}-T_{\mathrm{i}}\right), b_{1}=\frac{3 m-1}{6}\left(T_{\mathrm{s}}-T_{\mathrm{i}}\right) r_{\mathrm{bs}}, c_{1}=\frac{3 m+1}{6}$ $\left(T_{\mathrm{i}}-T_{\mathrm{s}}\right) r_{\mathrm{bs}}^{2}$.

Thus, the radius of hot-fluid-zone bottom, $r_{\mathrm{bh}}$, is

$$
r_{\mathrm{bh}}=\frac{-b_{1}+\sqrt{b_{1}^{2}-4 a_{1}\left(c_{1}-\frac{A^{\prime}}{\pi}\right)}}{2 a_{1}}
$$

\subsection{Reservoir Heat Efficiency}

When the wet steam reaches the bottom of the injection well and enters the pay zone, a part of heat carried by wet steam is lost to the overburden and underburden and the rest is retained in the steam zone and hot fluid zone as shown in Figure 5 . The reservoir heat efficiency is defined as the ratio of the heat retained in the pay zone to the total heat injected.

The heat growth of steam zone, $Q_{\mathrm{os}}$, is

$$
Q_{\mathrm{os}}=M_{\mathrm{R}}\left(T_{\mathrm{s}}-T_{\mathrm{i}}\right) V_{\mathrm{s}}=\frac{H}{3} M_{\mathrm{R}}\left(T_{\mathrm{s}}-T_{\mathrm{i}}\right)\left(m^{2}+m+1\right) A_{\mathrm{s} 2}
$$

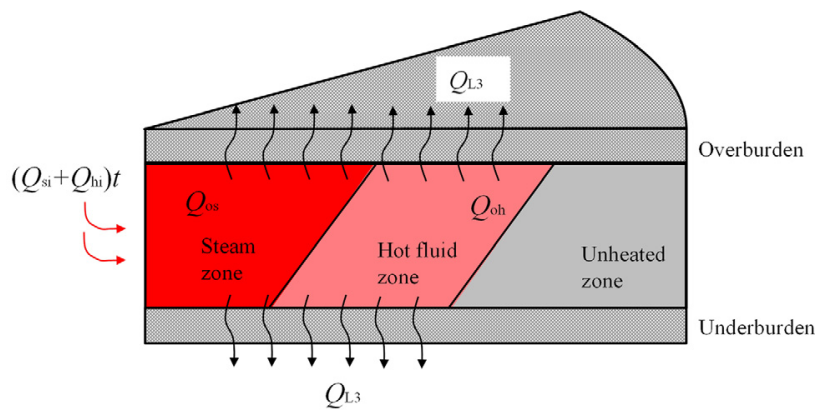

Figure 5

Schematic of heat losses in the pay zone.

The heat growth of hot fluid zone, $Q_{\mathrm{oh}}$, is

$$
\begin{aligned}
Q_{\mathrm{oh}}= & \int_{r_{\mathrm{bs}}}^{r_{\mathrm{bh}}} M_{\mathrm{R}} H \pi\left[a\left(r-r_{\mathrm{bs}}\right)+T_{\mathrm{s}}-T_{\mathrm{i}}\right] \\
& \left(2 r+m r_{\mathrm{bs}}-r_{\mathrm{bs}}\right) \mathrm{d} r \\
= & M_{\mathrm{R}} H A^{\prime}
\end{aligned}
$$

The reservoir heat efficiency of a wet steam injection well, $\eta$, is

$$
\begin{aligned}
\eta & =\frac{Q_{\mathrm{os}}+Q_{\mathrm{oh}}}{\left(Q_{\mathrm{si}}+Q_{\mathrm{hi}}\right) t} \times 100 \% \\
& =\left[\frac{M_{\mathrm{R}} H\left(T_{\mathrm{s}}-T_{\mathrm{i}}\right)\left(m^{2}+m+1\right) A_{\mathrm{s} 2}}{3\left(Q_{\mathrm{si}}+Q_{\mathrm{hi}}\right) t}-\frac{M_{\mathrm{R}} H A^{\prime}}{\left(Q_{\mathrm{si}}+Q_{\mathrm{hi}}\right) t}\right] \times 100 \%
\end{aligned}
$$

Incorporating Equations (15) and (26) into Equation (31), we can obtain

$\eta=\frac{1}{\left(1+h_{\mathrm{D}}\right) t_{\mathrm{D}}}\left\{\begin{array}{c}\frac{h_{\mathrm{D}}}{\beta}\left[\mathrm{e}^{\beta t_{\mathrm{D}}} \operatorname{erfc}\left(\sqrt{\beta t_{\mathrm{D}}}\right)+2 \sqrt{\frac{\beta t_{\mathrm{D}}}{\pi}}-1\right] \\ +\left[\mathrm{e}^{t_{\mathrm{D}}} \operatorname{erfc}\left(\sqrt{t_{\mathrm{D}}}\right)+2 \sqrt{\frac{t_{\mathrm{D}}}{\pi}}-1\right]\end{array}\right\} \times 100 \%$.

where $h_{\mathrm{D}}$ is the ratio of the latent heat of the steam to the sensible heat, namely, $h_{\mathrm{D}}=x L_{\mathrm{v}} / h_{\mathrm{w}}$.

When the steam override is not taken into account, that is if $m=1$, the Equation (32) can be simplified to

$$
\eta=\frac{1}{t_{\mathrm{D}}}\left[\mathrm{e}^{t_{\mathrm{D}}} \operatorname{erfc}\left(\sqrt{t_{\mathrm{D}}}\right)+2 \sqrt{\frac{t_{\mathrm{D}}}{\pi}}-1\right] \times 100 \%
$$

Equation (33) is exactly the same as the MarxLangenheim model, which shows that the Marx-Langenheim model is corresponding to a special case of the new model this paper proposes, and the new model should be 
TABLE 1

Parameters of reservoir properties.

\begin{tabular}{l|c|c}
\hline Parameter & Unit & Value \\
\hline Thickness of reservoir $(H)$ & $\mathrm{m}$ & 15 \\
\hline Initial reservoir temperature $\left(T_{\mathrm{i}}\right)$ & ${ }^{\circ} \mathrm{C}$ & 30 \\
\hline $\begin{array}{l}\text { Thermal conduction coefficient of } \\
\text { overburden and underburden }\left(\lambda_{\mathrm{s}}\right)\end{array}$ & $\mathrm{W} \cdot \mathrm{m}^{-1} \cdot{ }^{\circ} \mathrm{C}^{-1}$ & 1.73 \\
\hline $\begin{array}{l}\text { Thermal diffusivity of the } \\
\text { overburden and underburden }\left(\alpha_{\mathrm{s}}\right)\end{array}$ & $\mathrm{m}^{2} \cdot \mathrm{d}^{-1}$ & 0.089 \\
\hline Initial oil saturation $\left(s_{\mathrm{oi}}\right)$ & - & 0.75 \\
\hline Porosity $(\varphi)$ & - & 0.32 \\
\hline Effective permeability of oil $\left(k_{\mathrm{o}}\right)$ & $\mathrm{mD}$ & 500 \\
\hline Effective permeability of steam $\left(k_{\mathrm{st}}\right)$ & $\mathrm{mD}$ & 250 \\
\hline Heat capacity of sand rock $\left(C_{\mathrm{pr}}\right)$ & $\mathrm{J} \cdot \mathrm{kg}{ }^{-1} \cdot{ }^{\circ} \mathrm{C}^{-1}$ & 1000 \\
\hline Heat capacity of oil $\left(C_{\mathrm{po}}\right)$ & $\mathrm{J} \cdot \mathrm{kg}{ }^{-1} \cdot{ }^{\circ} \mathrm{C}^{-1}$ & 3000 \\
\hline Heat capacity of water $\left(C_{\mathrm{pw}}\right)$ & $\mathrm{J} \cdot \mathrm{kg}^{-1} \cdot{ }^{\circ} \mathrm{C}^{-1}$ & 4200 \\
\hline Density of sand rock $\left(\rho_{\mathrm{r}}\right)$ & $\mathrm{kg} \cdot \mathrm{m}^{-3}$ & 2500 \\
\hline Density of oil $\left(\rho_{\mathrm{o}}\right)$ & $\mathrm{kg} \cdot \mathrm{m}^{-3}$ & 890 \\
\hline Density of water $\left(\rho_{\mathrm{w}}\right)$ & $\mathrm{kg} \cdot \mathrm{m}^{-3}$ & 1000 \\
\hline Density of steam $\left(\rho_{\mathrm{st}}\right)$ & $\mathrm{kg} \cdot \mathrm{m}^{-3}$ & 14.7 \\
\hline Viscosity of steam $\left(\mu_{\mathrm{st}}\right)$ & $\mathrm{mPa} \cdot \mathrm{s}$ & 0.0132 \\
\hline \begin{tabular}{l}
$\left.\mu_{\mathrm{o}}^{*}\right)$ \\
\hline
\end{tabular} & $\mathrm{mPa} \cdot \mathrm{s}$ & 0.4 \\
\hline
\end{tabular}

closer to actual situation because of considering the steam override.

\section{RESULTS AND DISCUSSION}

\subsection{Model Verification}

In this section, to verify the mathematical model formulated in this paper, the computer program is designed based on it and a wet steam injection well W-1 in KMK oilfield, Aktyubinsk, northwest of Kazakhstan is used as an example to calculate the reservoir heat efficiency. The parameters of reservoir properties of well W-1 are listed in Table 1. In addition, the injection rate is $96 \mathrm{t} / \mathrm{d}$, and the steam temperature and steam quality at the bottom of the injection well are $248{ }^{\circ} \mathrm{C}$ and 0.75 , respectively.

The commercially available thermal reservoir simulator, STARS, developed by Computer Modelling Group (CMG), can be used to verify the correctness of other models.
The basic fluid and reservoir properties used in CMG STARS numerical model are listed in Table 1 and the relative permeability curve and the viscosity-temperature curve can be obtained in reference [5]. The grid size is $101 \times 101 \times 15$ and the corresponding block dimensions are $2 \mathrm{~m}, 2 \mathrm{~m}$ and $1 \mathrm{~m}$. The steam injection well is located in the center of the reservoir and four producers are located in the corners of the reservoir. In order to verify the correctness of the new formulated model, we compare our result with that of CMG STARS and that of the Marx-Langenheim model, as shown in Figure 6. As is seen from Figure 6, although the curve of reservoir heat efficiency predicted by our new model has the same general shape as the curve predicted by MarxLangenheim model, it provides calculated reservoir heat efficiency somewhat lower. This is because the effect of steam override, which is taken into account in our new model but not in the Marx-Langenheim model, increases areas of heated-region top and heated-region bottom directly getting in touch with hot fluid and results in more heat lost to the overburden and underburden. Therefore, the MarxLangenheim model always gives a greater value for the reservoir heat efficiency compared to our new model. Moreover, it is observed that the reservoir heat efficiency predicted by our new model is in better agreement with the CMG STARS simulation result as compared to the Marx-Langenheim model. Specially, a relative error less than $4.1 \%$ supports the reliability and correctness of the new model. Meanwhile, there are some differences between our new model and CMG STARS simulation result. The new model gives a lower value of reservoir heat efficiency in the beginning and a higher value in the later stage. According to our analyses, the reason for the lower value in the beginning may be that the degree of steam override is actually very small in the early stage and becomes more and more severe with injection time; however, the steam override coefficient used in the new model keeps constant all the time. The higher value in the later stage is largely due to the simplification of the shape of steam zone. In this paper, we suppose that the steam zone has the shape of the frustum of a cone, which largely reduces the solution difficulties. However, the front of steam zone is much more like a parabola rather than a tilted straight line in the later steam injection period; that is, the steam zone is much more like funnel instead of the frustum of a cone or cylinder as the Marx-Langenheim model proposed. Although the deviation between our new model and CMG STARS simulation result exists, it is much smaller than that between the MarxLangenheim model and CMG STARS simulation result and it is acceptable in engineering calculation.

\subsection{Analyses of the Predicted Results}

Through Equation (4), the relationship of the steam override coefficient versus the dimensionless shape factor with 


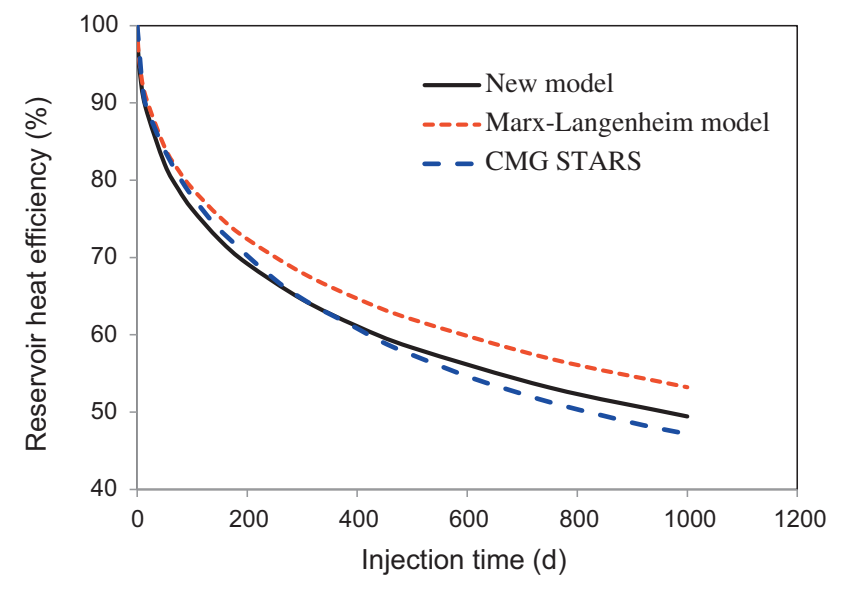

Figure 6

Comparison of reservoir heat efficiency predicted by the new model, Marx-Langenheim model and CMG STARS.

different mobility ratio is shown in Figure 7a. It is easily found from Figure $7 \mathrm{a}$ that the steam override coefficient decreases with the dimensionless shape factor but increases with mobility ratio. Furthermore, for the dimensionless shape factor greater than 3 , the decrease of steam override coefficient with the dimensionless shape factor is unremarkable, but it is significant when the dimensionless shape factor is less than 3. In addition, van Lookeren pointed out that the mobility ratio is usually small for common heavy oil reservoirs and therefore it can be ignored, that is, $M^{*}=0$. Thus, in order to make it much easier to obtain the steam override coefficient instead of by solving nonlinear equation, nonlinear regression for the relationship between the steam override coefficient and the dimensionless shape factor under the condition of $M^{*}=0$ is carried out with software Origin. The regression curve, which shows quite good match and has the relative error of less than $1.5 \%$ as illustrated in Figure $7 \mathrm{~b}$, is given as

$$
m=8.3355 A_{\mathrm{RD}}^{-2}-12.171 \mathrm{e}^{-A_{\mathrm{RD}}}+1.1277
$$

Results of Equation (32) are plotted in Figure 8. It can be found from Figure 8a that for a given value of the ratio of the latent heat of steam to the sensible heat $\left(h_{\mathrm{D}}=1.28\right)$, the reservoir heat efficiency decreases with steam override coefficient, $m$. The main reason can be explained as follows: the larger the steam override coefficient, that is, the more severe of steam override, the larger areas of heated-region top and bottom directly contact with hot fluid at the same cumulative heat injection, which results in more heat losses to the overburden and underburden. Moreover, it should be noted that the upper bound for reservoir heat efficiency is exactly that predicted by Marx-Langenheim model in which the steam override is not taken into account; namely, the steam override coefficient equals to 1 and the shape of steam zone is a cylinder. The lower bound for reservoir heat efficiency represents the most severe of steam override; that is, the steam override coefficient equals to infinity and the shape of steam zone is a cone. The actual reservoir heat efficiency of wet steam injection process is between lower bound and upper bound, with the shape of steam zone being the frustum of a cone proposed by our new model. As shown in Figure 8 b, for a given value of steam override coefficient $(m=6)$, the reservoir heat efficiency decreases with the ratio of the latent heat of steam to the sensible heat, $h_{\mathrm{D}}$. The lower bound, with $h_{\mathrm{D}}$ equals to infinity, gives the reservoir heat efficiency when there is no heat stored in the pay zone outside the steam zone. In other words, the lower bound represents the heat efficiency of steam zone only. The upper bound, with $h_{\mathrm{D}}$ equal to zero, gives the reservoir heat efficiency when the steam quality equals to zero; that is, it represents the reservoir heat efficiency of hot water injection process, which shows that heating by hot water is always more efficient than heating by steam.

\subsection{Influential Factors Analysis of Reservoir Heat Efficiency}

In this section, the influential factors of reservoir heat efficiency, such as injection rate, steam quality and reservoir thickness, are analyzed based on the above validated model. The basic parameters used for the following calculation are displayed in Table 1.

\subsubsection{Effect of Injection Rate}

Figure 9 shows the effect of injection rate on the reservoir heat efficiency. As shown in Figure 9a, it is clearly observed that the reservoir heat efficiency increases as the injection rate increases, which is not in accord with the conclusion proposed by the Marx-Langenheim model, based on Equation (33), that the reservoir heat efficiency is independent of the injection rate. The reason for this difference is that our new model takes account of the effect of steam override, and the steam override coefficient decreases with injection rate, as shown in Figure 9b. In addition, to enhance the reservoir heat efficiency, the injection rate should be increased as much as possible. However, it should be pointed out that the injection rate is always in positive correlation to the injection pressure, which means fast injection rate needs high injection pressure. Once the injection pressure is greater than the reservoir fracture pressure, micro fractures and plugging channeling will be produced, resulting in the effect of wet steam injection getting worse. Hence, the injection 


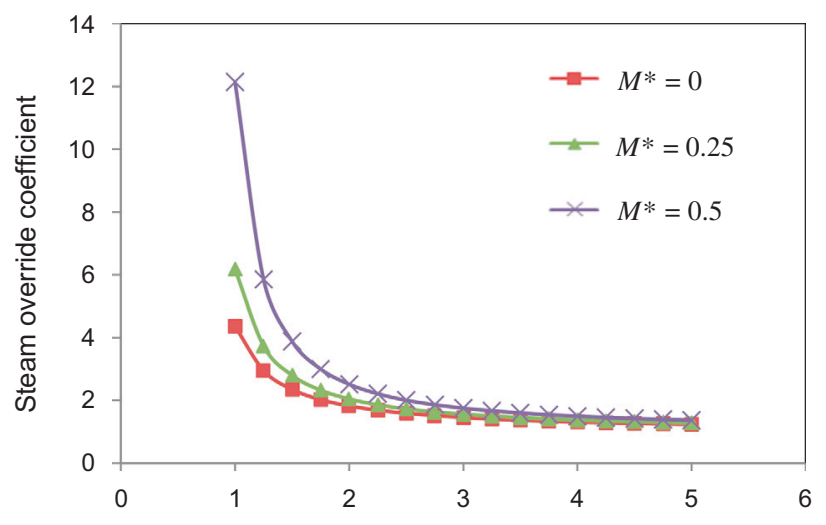

a)

Dimensionless shape factor

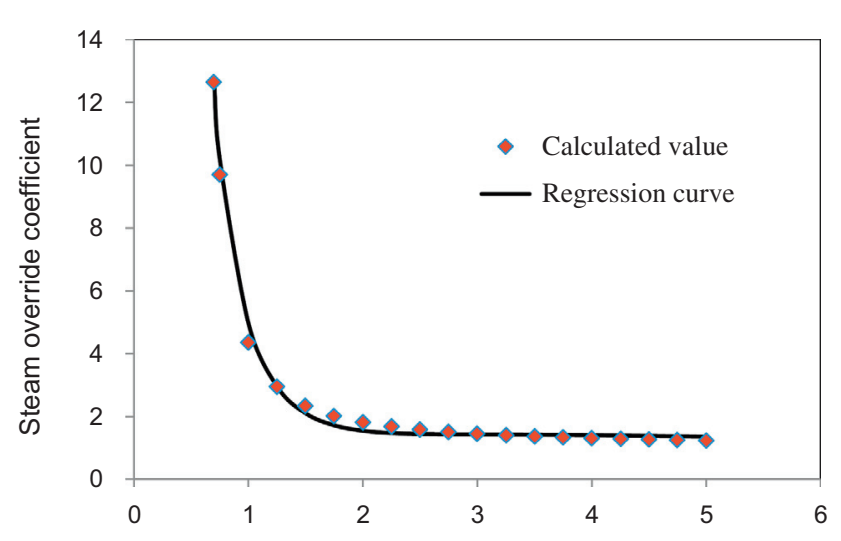

b)

Figure 7

Steam override coefficient $v s$. dimensionless shape factor with different mobility ratio a) and regression curve with $M^{*}=0 \mathrm{~b}$ ).
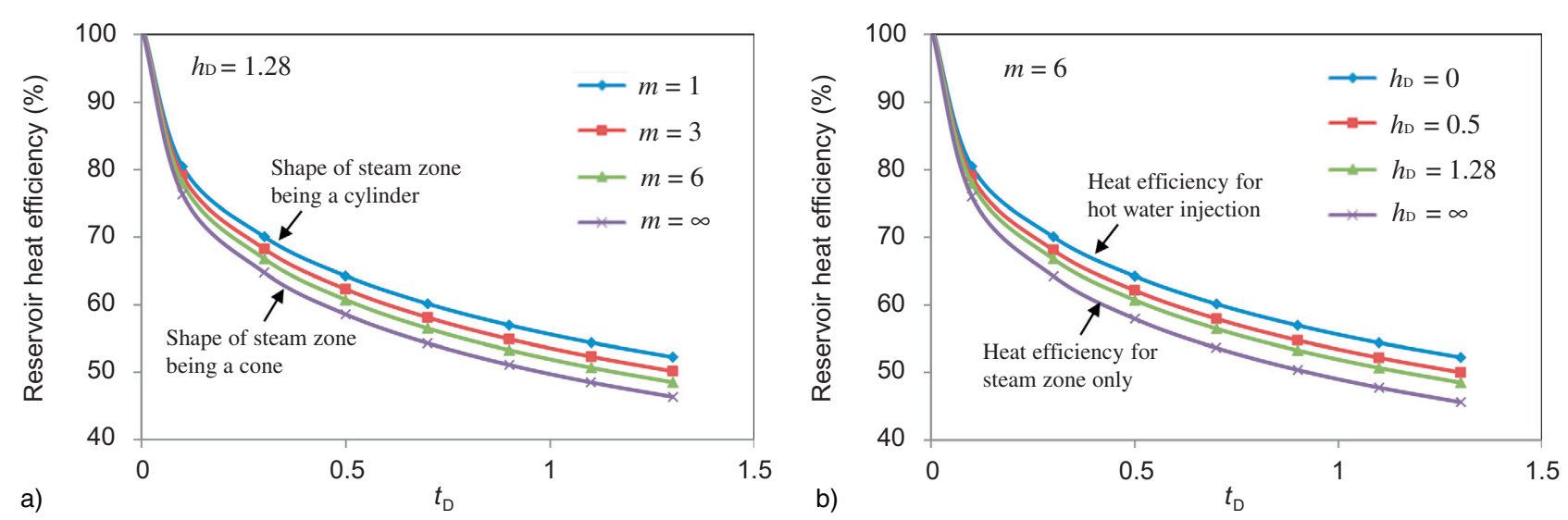

Figure 8

Reservoir heat efficiency $v s$. dimensionless time with different $m$ and $h_{\mathrm{D}}$.

rate should be restricted to the injection pressure less than reservoir fracture pressure.

\subsubsection{Effect of Steam Quality}

Figure 10 shows the effect of steam quality on the reservoir heat efficiency. Figure 10a gives the relationship of the reservoir heat efficiency versus steam quality and it shows that the reservoir heat efficiency has little to do with steam quality. Although the conclusion about the effect of the steam quality on the reservoir heat efficiency proposed by our new model and the Marx-Langenheim model is almost the same, the reason for it is entirely different. According to Equation (33), the Marx-Langenheim model believes that the reservoir heat efficiency is independent of the steam quality while our new model, based on Equation (32), demonstrates that the steam quality has impact on the ratio of the latent heat of steam to the sensible heat, $h_{\mathrm{D}}$, and the steam override coefficient, $m$. From Figure 10b, the steam override coefficient decreases but the ratio of the latent heat of steam to the sensible heat increases as the steam quality increases. Besides, the steam override coefficient and the ratio of the latent heat of steam to the sensible heat play the same role on the reservoir heat efficiency as shown in Figure 8, resulting that the steam quality contributes very little to the reservoir heat efficiency. It should be stressed that although the steam quality has little impact on the reservoir heat efficiency, attempts to maximize steam quality may be justified for the reason that more oil is recovered at higher steam quality because of correspondingly larger steam zone. 

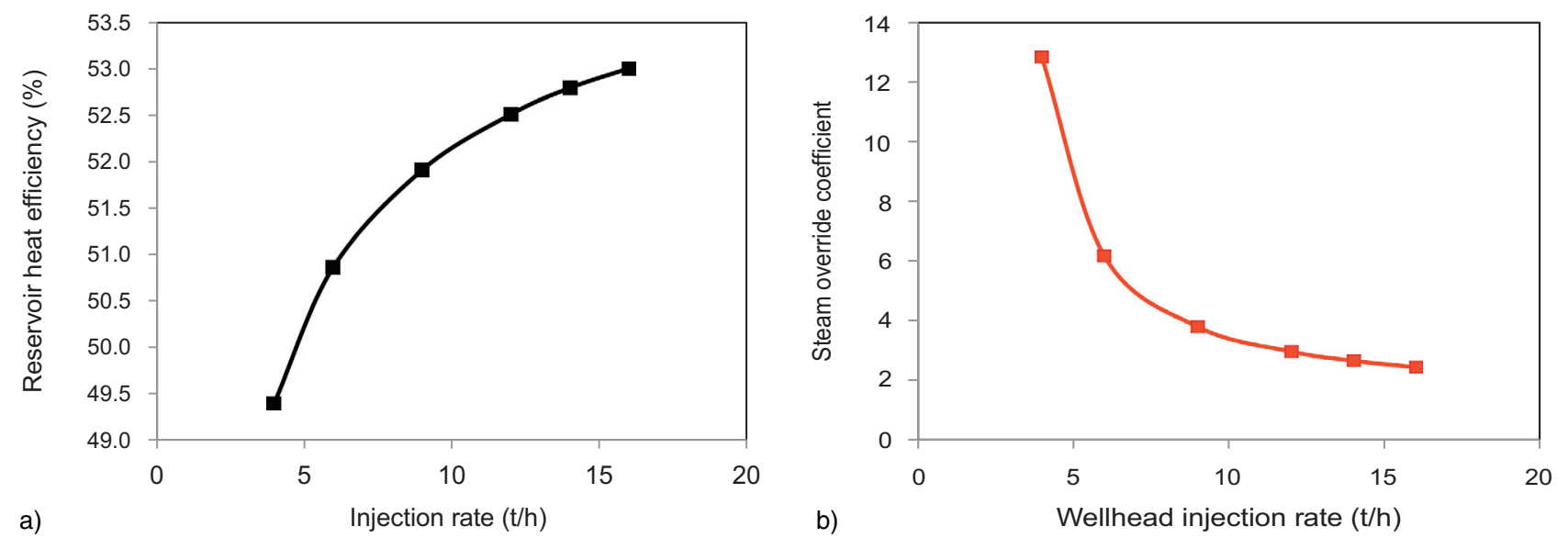

Figure 9

Effects of injection rate on a) reservoir heat efficiency at injection time of $1000 \mathrm{~d}$ and b) steam override coefficient.
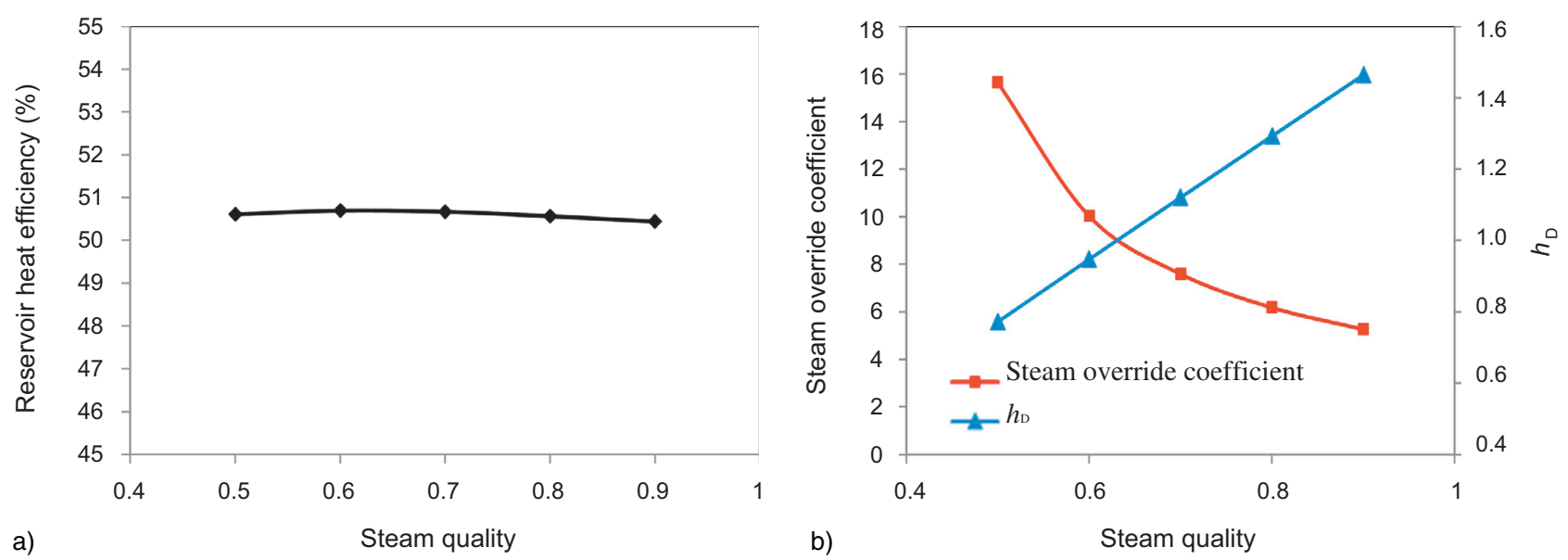

Figure 10

Effects of steam quality on a) reservoir heat efficiency at injection time of $1000 \mathrm{~d}$ and b) steam override coefficient and $h_{\mathrm{D}}$.

\subsubsection{Effect of Reservoir Thickness}

The reservoir thickness has a great effect on the reservoir heat efficiency as shown in Figure 11. It is observed from Figure 11a that the larger the reservoir thickness is, the greater the reservoir heat efficiency becomes. For instance, when the reservoir thickness equals to $10 \mathrm{~m}$, the reservoir heat efficiency is about $40.8 \%$ at injection time of $1000 \mathrm{~d}$, while it increases to $55.5 \%$ when the reservoir thickness increases to $20 \mathrm{~m}$. The reason is that, according to Equations (3) and (4), although the steam override coefficient increases with the reservoir thickness, the areas of heated-region top and bottom decrease with the reservoir thickness at the same cumulative heat injection, as the Figure $11 \mathrm{~b}$ shows, which leads to smaller heat lost to the overburden and underburden. Consequently, to ensure a successful wet steam injection project, the reservoir thickness should not be too small.

\subsection{Application of the Model}

As is shown above, the reservoir heat efficiency is affected by steam injection parameters during steam injection process. The new model can be used to evaluate the heat 

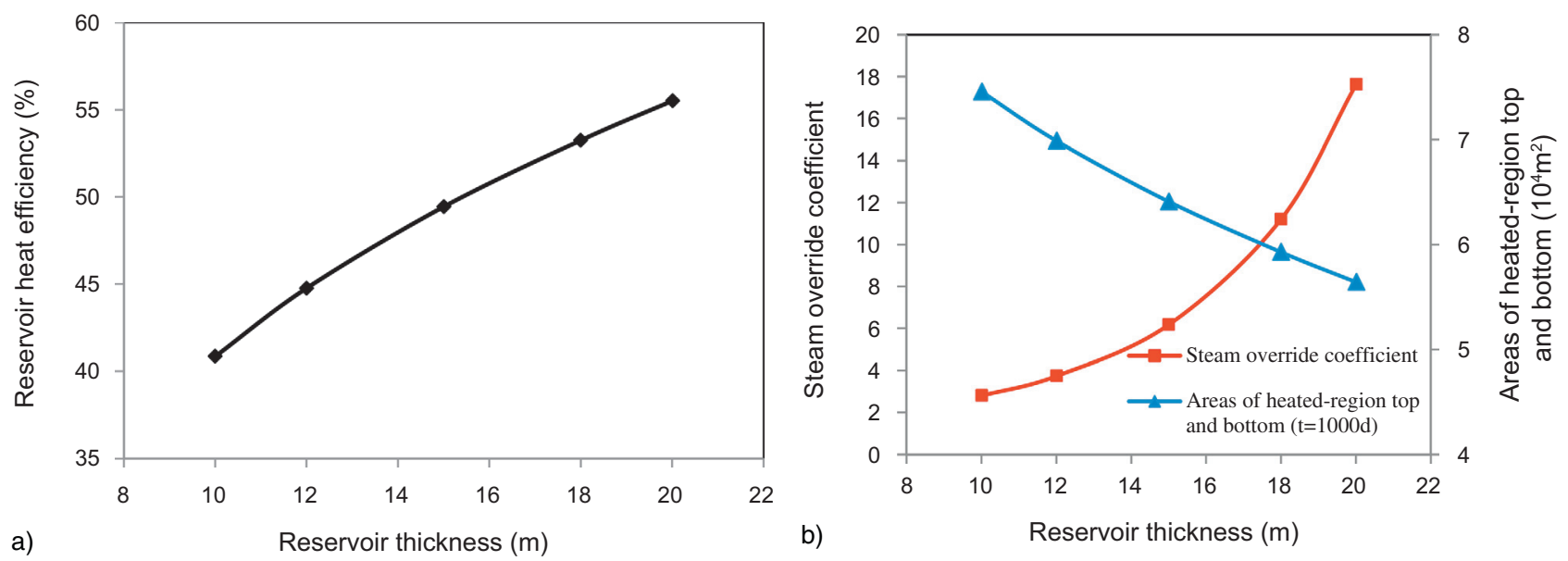

Figure 11

Effects of reservoir thickness on a) reservoir heat efficiency at injection time of $1000 \mathrm{~d}$ and b) steam override coefficient and areas of heatedregion top and bottom.

efficiency of injected steam in heavy oilfield quickly and accurately and adjust the steam injection parameters. Taking the steam injection well W-1 in KMK oilfield as an example, 0.75 -quality steam is injected into the reservoir at a mass flow rate of $96 \mathrm{t} / \mathrm{d}$ with steam temperature of $248{ }^{\circ} \mathrm{C}$. The reservoir heat efficiency at injection time of $1000 \mathrm{~d}$ is about $49 \%$ calculated by the new model while about $54 \%$ by Marx-Langenheim model, which means extra $5 \%$ of heat carried by injected steam is lost as a result of steam override. Known from influential factors analysis of the reservoir heat efficiency, the steam injection well W-1 should increase injection rate properly to decrease the effect of steam override. When the steam injection rate of well $\mathrm{W}-1$ increases to $216 \mathrm{t} / \mathrm{d}$ as the adjoining steam injection well in KMK oilfield, the reservoir heat efficiency will increase to $52 \%$.

\section{CONCLUSIONS}

In this study, an improved model for predicting heat efficiency of wet steam injection in heavy oil reservoirs with the consideration of steam override has been developed. We firstly established the equation for steam override coefficient based on van Lookeren's steam override theory and then radius of steam zone and hot fluid zone were derived according to a more realistic temperature distribution and an energy balance in the pay zone. On this basis, the equation for the reservoir heat efficiency in wet steam injection process considering steam override was proposed. After the new analytical model was verified by comparing the new model results with those of another analytical model and a thermal simulator, the influential factors of reservoir heat efficiency were analyzed in detail. The main conclusions can be drawn as follows:

(1) the proposed new mathematical model was proved to be reliable in engineering calculation and can be simplified to the classic model for reservoir heat efficiency (MarxLangenheim model) under the condition of the steam override being not taken into account, showing that the Marx-Langenheim model is corresponding to a special case of this new model. In other words, this new model has a wide range of application;

(2) although the curve of reservoir heat efficiency predicted by our new model has the same general shape as the curve predicted by Marx-Langenheim model, it provides reservoir heat efficiency somewhat lower compared to the Marx-Langenheim model because of considering steam override;

(3) for a given value of steam override coefficient, the reservoir heat efficiency decreases with dimensionless time, and at the same dimensionless time, the reservoir heat efficiency decreases with steam override coefficient;

(4) the reservoir heat efficiency is dependent on the injection rate and steam quality, and high injection rate can slightly improve reservoir heat efficiency;

(5) the reservoir thickness affects the reservoir heat efficiency significantly, and the larger the reservoir thickness is, the greater the reservoir heat efficiency becomes. In order to ensure a successful wet steam injection project, the reservoir thickness should not be too small. 


\section{ACKNOWLEDGMENTS}

This work was supported by the Major Projects of China Petroleum Group Company (2011E-2504).

\section{REFERENCES}

1 Liu W.Z. (1997) Steam injection for thermal recovery of heavy oils, 1st edn., Petroleum Industry Press, Beijing.

2 Vega Riveros G.L., Barrios H. (2011) Steam injection experiences in heavy and extra-heavy oil fields, Venezuela, in Proceedings of SPE Heavy Oil Conference and Exhibition, 12-14 December, Kuwait City, Kuwait, SPE-150283-MS.

3 Wei S.L., Cheng L.S., Huang W.J., Huang S.J., Liu S. (2014) Prediction for steam chamber development and production performance in SAGD process, J. Natural Gas Sci. Eng. 19, 303-310.

4 Zeng Y.Q., Liu S.Z., Wang Q., et al. (2006) Overview of heavy oil cyclic steam stimulation recovery technology, Special Oil \& Gas Res. 13, 6, 5-9.

5 He C.G., Mu L.X., Xu A.Z., Sidong F. (2015) A new model of steam soaking heating radius and productivity prediction for heavy oil reservoirs, Acta Petrolei Sinica 36, 12, 1564-1570.

6 Ziegler V.M., Crookston R.B., Sanford S.J., Merrell J.M. (1993) Recommended practices for heat management of steamflood projects, in Proceedings of the SPE International Thermal Operations Symposium, SPE-25808-MS, 8-10 Feb., Bakersfield, CA, pp. 297-318.

7 Wu Z.B., Pang Z.X., Liu H.Q., Wang D., Wang C., Wang C., Ye Z., Chen Y. (2015) A visible experiment on adoption of high-temperature gel for improving the development effect of steam flooding in heavy oil reservoirs, Acta Petrolei Sinica 36, 11, 1421-1426.

8 Miura K., Wang J. (2010) An analytical model to predict cumulative steam oil ratio (CSOR) in thermal recovery SAGD process, in Canadian Unconventional Resources and International Petroleum Conference, 21 Oct., Galgary, Alberta, Canada, SPE-137604-MS.

9 Liu H.Q., Fan Y.P., Zhao D.W., et al. (2008) Principles and methods of thermal oil recovery technology, 1st edn., Chin. Univ. of Petro. Press, Dongying.

$10 \mathrm{Gu}$ H., Cheng L.S., Huang S.J. (2014) New algorithm for thermophysical parameters and heat loss along wellbore during steam injection, Chin. J. Comput. Phys. 31, 4, 449-454.
11 Prats M. (1969) The heat efficiency of thermal recovery process, J. Pet. Technol. 21, 323-332.

12 Ramey H.J. (1962) Wellbore heat transmission, J. Pet. Technol. 14, 427-435.

13 Satter A. (1965) Heat losses during flow of steam down a wellbore, J. Pet. Technol. 17, 845-851.

14 Holst P.H., Flock D.L. (1966) Wellbore behavior during saturated steam injection, J. Can. Pet. Technol. 5, 184-193.

15 Gu H., Cheng L.S., Huang S.J., Du B.J., Hu C.H. (2014) Prediction of thermophysical properties of saturated steam and wellbore heat losses in concentric dual-tubing steam injection wells, Energy 75, 419-429.

16 Gu H., Cheng L.S., Huang S.J., Li B.K., Fang W.C., Hu C.H. (2015) Steam injection for heavy oil recovery: modeling of wellbore heat efficiency and analysis of steam injection performance, Energy Convers. Manage. 97, 166-177.

$17 \mathrm{Gu}$ H., Cheng L.S., Huang S.J. (2014) New algorithm for thermophysical parameters and heat loss along wellbore during steam injection, Chin. J. Comput. Phys. 31, 4, 449-454.

18 Aydelotte S.R., Gary A. (1983) A simplified predictive model for steamdrive performance, J. Pet. Technol. 35, 991-1002.

19 Baker P.E. (1969) An experimental study of heat flow in steam flooding, Soc. Pet. Eng. J. 9, 89-99.

20 Marx J.W., Langenheim R.H. (1959) Reservoir heating by hot fluid injection petroleum transactions, AIME 216, 312-315.

21 van Lookeren J. (1977) Calculation methods for linear and radial steam flow in oil reservoirs, Soc. Pet. Eng. J. 23, 1-16.

22 Doscher T.M., Ghassemi F. (1983) The influence of oil viscosity and thickness on the steam drive, J. Pet. Technol. 35, 291-298.

23 Neuman C.H. (1975) A mathematical model of the steam drive process-applications, in Proceeding of SPE California Regional Meeting, 2-4 April, Ventura, California, SPE-4757-MS.

24 Vogel J.V. (1984) Simplified heat calculations for steamfloods. AIME 36, 1127-1136.

25 Carslaw H.S., Jaeger J.C. (1986) Conduction of heat in solids, 2nd edn., Oxford University Press, USA, New York.

26 Roger M.B. (1991) Thermal recovery of oil and bitumen, Prentice-Hall, Inc., USA.

Manuscript submitted in July 2016

Manuscript accepted in December 2016

Published online in February 2017

Cite this article as: C. He, L. Mu, Z. Fan, A. Xu, B. Zeng, Z. Ji and H. Han (2017). An Improved Steam Injection Model with the Consideration of Steam Override, Oil Gas Sci. Technol 72, 6. 